\title{
Providing High-Quality Care for Limited English Proficient Patients: The Importance of Language Concordance and Interpreter Use
}

\author{
Quyen Ngo-Metzger, $M D, M P H^{7}$, Dara H. Sorkin, $P h D^{7}$, Russell S. Phillips, $M D^{2}$, \\ Sheldon Greenfield, $\mathrm{MD}^{7}$, Michael P. Massagli, $\mathrm{PhD}^{3}$, Brian Clarridge, $\mathrm{PhD}^{4}$, and Sherrie H. Kaplan, \\ $P h D^{1}$
}

\begin{abstract}
'Division of General Internal Medicine and Primary Care and the Center for Health Policy Research, University of California, Irvine School of Medicine, Irvine, CA, USA; ${ }^{2}$ Division of General Medicine and Primary Care, Beth Israel Deaconess Medical Center, Harvard Medical School, Boston, MA, USA; ${ }^{3}$ Dana Farber Cancer Institute, Boston, MA, USA; ${ }^{4}$ The Center for Survey Research, University of Massachusetts-Boston, Boston, MA, USA.
\end{abstract}

\begin{abstract}
BACKGROUND: Provider-patient language discordance is related to worse quality care for limited English proficient (LEP) patients who speak Spanish. However, little is known about language barriers among LEP Asian-American patients.

OBJECTIVE: We examined the effects of language discordance on the degree of health education and the quality of interpersonal care that patients received, and examined its effect on patient satisfaction. We also evaluated how the presence/absence of a clinic interpreter affected these outcomes.
\end{abstract}

DESIGN: Cross-sectional survey, response rate $74 \%$.

PARTICIPANTS: A total of 2,746 Chinese and Vietnamese patients receiving care at 11 health centers in 8 cities.

MEASUREMENTS: Provider-patient language concordance, health education received, quality of interpersonal care, patient ratings of providers, and the presence/absence of a clinic interpreter. Regression analyses were used to adjust for potential confounding.

RESULTS: Patients with language-discordant providers reported receiving less health education $(\beta=0.17, p<$ $0.05)$ compared to those with language-concordant providers. This effect was mitigated with the use of a clinic interpreter. Patients with language-discordant providers also reported worse interpersonal care $(\beta=$ $0.28, p<0.05$ ), and were more likely to give low ratings to their providers (odds ratio $[\mathrm{OR}]=1.61 ; \mathrm{CI}=0.97-2.67$ ). Using a clinic interpreter did not mitigate these effects and in fact exacerbated disparities in patients' perceptions of their providers.

CONCLUSION: Language barriers are associated with less health education, worse interpersonal care, and lower patient satisfaction. Having access to a clinic interpreter can facilitate the transmission of health education. However, in terms of patients' ratings of their providers and the quality of interpersonal care, having an interpreter present does not serve as a substitute for language concordance between patient and provider.

KEY WORDS: quality of care; satisfaction; interpersonal care; interpreters; health education; language barriers; limited English proficiency; Asian American.
J Gen Intern Med 22(Suppl 2):324-30

DOI: $10.1007 / \mathrm{s} 11606-007-0340-Z$

(C) Society of General Internal Medicine 2007

\section{INTRODUCTION}

According to the 2000 census, approximately 47 million people in the United States speak a language other than English at home and over 21 million have limited English-language skills. ${ }^{1}$ Limited English proficient (LEP) individuals often have worse access to care $^{2-5}$ and rate their health care more negatively ${ }^{6-9}$ compared to English speakers. Language barriers have been found to adversely impact the quality of medical care that patients receive, resulting in longer hospital stays, ${ }^{10}$ more medical errors, ${ }^{11}$ and lower patient satisfaction. ${ }^{12,13}$

One way to overcome language barriers is to provide LEP individuals with access to medical providers who speak their language. Research has shown that patients with diabetes and hypertension reported better health outcomes when their physicians spoke their native language. ${ }^{14}$ Spanish-speaking patients who saw language-concordant physicians asked more questions and had better understanding than those who saw language-discordant (non-Spanish-speaking) physicians. ${ }^{15}$ Patients with language-discordant providers have been found to be less satisfied with their care and less likely to return for follow-up care. ${ }^{7-9,16}$ In other studies, LEP patients with language-discordant physicians had more problems understanding medication instructions, ${ }^{17}$ and had more medicationrelated problems. ${ }^{18}$

Although language-concordant medical visits are ideal, most LEP patients do not have access to providers who speak their language. ${ }^{19}$ Until the provider work force becomes more racially/ethnically and linguistically diverse, many LEP patients will have medical providers who speak only English. For these language-discordant medical encounters, some type of interpreter service is often used. Even with the use of an interpreter, the quality of provider-patient interpersonal care and the degree of health education received have been found to be suboptimal. ${ }^{20,21}$ However, most of the studies on language barriers and interpreter use have been conducted among Spanish-speaking patients and their monolingual Englishspeaking providers. 
Asian Americans, many of whom are immigrants and have limited English proficiency, are one of the fastest growing demographic groups in the United States. ${ }^{22}$ Yet little is known about language barriers and interpreter use among AsianAmerican patients. In this study, we wanted to assess the quality of care of LEP Chinese and Vietnamese American patients who had providers who did not speak their language (language-discordant) as compared to those with languageconcordant providers. We examined whether LEP patients with language-discordant providers received as much health education as those with language-concordant providers. We also examined whether language discordance was associated with lower-quality interpersonal care and lower patient satisfaction. Furthermore, for language-discordant visits, we sought to evaluate how the presence or absence of a clinic interpreter affected patients' receipt of health education, the quality of interpersonal care, and ratings of providers.

\section{METHODS}

\section{Setting}

From January to March 2002, we mailed surveys to Chinese and Vietnamese Americans who had an office visit at 1 of 11 community health centers within the prior 30 days. The 11 community health centers were located across the United States in 8 urban settings near Chinese or Vietnamese ethnic communities. Locations included Los Angeles, Oakland, Seattle, Chicago, Houston, New York City, Worcester (MA), and Boston. Details of survey development and administration have been detailed elsewhere. ${ }^{23-25}$ In brief, the 81 -item survey assessed patients' perspectives and experiences with health care using questions similar to those used by the Picker Surveys ${ }^{26}$ and the Consumer Assessment of Healthcare Providers and Systems (CAHPS) Surveys. ${ }^{27}$ Through focus groups and extensive pilot testing, we tailored the survey to better reflect the unique perspectives of Chinese and Vietnamese immigrants. ${ }^{24,25}$ Patients could respond in English or in their native language (Vietnamese, Cantonese-, or Mandarin-Chinese). Of 4,410 surveys sent, 3,258 (74\%) were completed and returned.

\section{Survey Measures}

We asked patients questions about their demographic characteristics, such as years living in the United States, education level, and English-language proficiency. English proficiency was determined by asking "How well do you speak English?" Response categories were: Very well/ Well/ Not well/ Not at all. Interpreter use was determined by the question "During lyour] most recent visit, did you use one of the clinic's interpreters?" Response categories were: yes/no. We also asked whether patients saw their usual provider during the most recent visit.

Independent Variables of Interest. Language concordance or discordance was determined by 2 questions: 1) "What language are you most comfortable speaking?" Response options were: "English, Cantonese Chinese, Mandarin Chinese, Vietnamese, or Another Language;" and 2) "On your most recent visit, what language did the doctor or nurse speak during your examination?" Response options were: "English, Cantonese Chinese, Mandarin Chinese, Vietnamese, and Other." Language concordance was determined to have occurred when the patient and the provider spoke the same language. As Cantonese and Mandarin are 2 distinct oral Chinese dialects, concordance was determined to have occurred only if the patient and provider spoke the same Chinese dialect. Because we were only interested in patients who were LEP, we excluded those whose primary language was English $(n=75)$, and those who spoke English very well/well $(n=322)$ or had missing language data $(n=12)$. We also excluded those whose primary languages were not Cantonese, Mandarin, or Vietnamese, or for whom language concordance could not be determined $(n=103)$. Our final analytic sample included 2,746 patients.

Outcome Measures. The dependent variables of interest included: 1) the degree of health education that patients received; 2) the quality of interpersonal care; and 3) ratings of providers. Health education received in the last 12 months was assessed by a 3-item scale that asked whether providers talked to patients about diet, exercise, and smoking $(0=$ yes, $1=n o)$ (Table 1). Items were summed to create a composite index of health education. Cronbach's alpha for this scale was 0.72. The quality of interpersonal care was measured by a nine-item scale. ${ }^{25}$ Patients were asked whether or not each of 9 events occurred during their most recent visit $(0=$ yes, $1=$ no) (Table 1$)$. Items were summed to create a composite index of interpersonal care. Cronbach's alpha for internal consistency reliability of this scale was 0.73 . Patient satisfaction was assessed by patient rating of the provider, which was determined by asking "How would you rate the doctor or nurse who examined you during this visit?" Response categories were: "Excellent, Very good, Good, Fair, and Poor." Responses were dichotomized $(0=$ excellent, very good, good, $1=$ fair or poor).

\section{Statistical Analysis}

We conducted descriptive analyses comparing patients who were language-concordant with their providers to those who were language-discordant, using either chi-square or $t$ test statistics where appropriate.

Then we examined the association between language concordance/discordance and the degree of health education received. Specifically, we conducted unadjusted and adjusted multiple regressions, testing models that examined whether language concordance/discordance was an independent predictor of the degree of health education received. A priori, we included in the adjusted model as covariates other possible predictors of health education including patient demographics (age, gender, language, marital status, education, years in the United States), and whether patients saw their usual provider at the visit. We then repeated the analyses examining the effect of having an interpreter present or not in the languagediscordant visits compared to those that were language concordant.

In a similar manner, we conducted regression analyses for the other 2 outcomes (the quality of interpersonal care and the rating of the provider). In all cases, we examined language discordance as the main predictor variable, and we constructed our outcome variables such that higher scores represented lower values or worse ratings. All analyses were 
Table 1. Measures of Health Education and Interpersonal Care

Scales

Internal-Consistency

Reliability

Health Education

In the last 12 months

1. ... did your doctor or nurse talk with you about how much or what kind of food you eat?

2. ... did your doctor or nurse talk with you about how much or what kind of exercise you get?

3. ... did your doctor or nurse talk with you about smoking?

Interpersonal Care

On your most recent visit, did the doctor or nurse who examined you...

Cronbach's Alpha $=0.73$

1. ... treat you with courtesy and respect?

2. ... allow you enough time to explain the reasons for your visit?

3. ... explain things in a way you could understand?

4.... spend enough time with you?

5. ... give you as much information about your health and treatment as you wanted?

6. ... explain what to do if symptoms continue or get worse?

7. Did you have any questions about your care that you wanted to ask but did not? (R)

8. Did you have any questions about your mental health that you wanted to ask but did not? (R)

9. Did anyone in your family have questions about your care and treatment that they wanted to ask but did not? (R)

Response options: Yes/No

$(R)=$ Reverse coded

conducted using SAS 8.1 and SAS-callable SUDAAN to account for the sampling design and clustering by clinic site. ${ }^{28,29}$

\section{RESULTS}

\section{Description of the Study Sample}

The 2,746 patients in the study had a mean age of 53.8 years. Over 99\% were foreign-born, and 59\% had 9 years of education or less. Table 2 shows the demographic and utilization characteristics of the patients included in the study by language concordance/discordance. Compared to patients who had language-concordant providers, language-discordant patients were younger, had lived in the United States for fewer years, and had more years of education. Furthermore, language-discordant patients were more likely to be Mandarinspeaking or Vietnamese-speaking and less likely to be Cantonese-speaking compared to language-concordant patients. Finally, language-discordant patients were less likely to have seen their usual doctor at the most recent visit compared to language-concordant patients.

Table 3 shows the association between language discordance and the degree of health education received. Language-

Table 2. Demographic and Utilization Characteristics by Language Concordance $(N=2,746)$

\begin{tabular}{|c|c|c|c|}
\hline & Concordant & Discordant & $p$ value $a$ \\
\hline & $N=2187$ & $N=559$ & \\
\hline \multicolumn{4}{|l|}{ Gender } \\
\hline Female $(n=1,831)$ & $68.74 \%$ & $65.70 \%$ & \multirow[t]{2}{*}{$p=.39$} \\
\hline Male $(n=915)$ & $31.26 \%$ & $34.30 \%$ & \\
\hline Age $(n=2,743)$ & $54.42 \mathrm{yrs}$ & 50.37 yrs & $p<.002$ \\
\hline \multicolumn{4}{|l|}{ Language } \\
\hline Cantonese $(n=1,010)$ & $66.49 \%$ & $39.43 \%$ & \multirow[t]{3}{*}{$p<.001$} \\
\hline Mandarin $(n=612)$ & $15.71 \%$ & $20.91 \%$ & \\
\hline Vietnamese $(n=1124)$ & $17.80 \%$ & $39.66 \%$ & \\
\hline Years in the United States $(n=2,706)$ & $11.64 \mathrm{yrs}$ & 9.70 yrs & $p<.001$ \\
\hline \multicolumn{4}{|l|}{ Marital status: } \\
\hline Married $(n=2,048)$ & $75.17 \%$ & $72.02 \%$ & \multirow[t]{2}{*}{$p=.72$} \\
\hline Not Married $(n=654)$ & $24.83 \%$ & $25.98 \%$ & \\
\hline \multicolumn{4}{|l|}{ Education } \\
\hline Less than or equal to 9 years $(n=1,595)$ & $66.25 \%$ & $55.73 \%$ & \multirow[t]{2}{*}{$p<.002$} \\
\hline More than 9 years $(n=1,088)$ & $33.75 \%$ & $44.27 \%$ & \\
\hline \multicolumn{4}{|l|}{ English language proficiency } \\
\hline Not well $(n=1,593)$ & $52.28 \%$ & $64.30 \%$ & \multirow[t]{2}{*}{$p<.01$} \\
\hline Not at all $(n=1,153)$ & $47.72 \%$ & $35.70 \%$ & \\
\hline \multicolumn{4}{|l|}{ Saw usual doctor at most recent visit } \\
\hline Yes $(n=2,321)$ & $86.22 \%$ & $77.61 \%$ & \multirow[t]{2}{*}{$p<.01$} \\
\hline No $(n=351)$ & $13.78 \%$ & $22.39 \%$ & \\
\hline \multicolumn{4}{|l|}{ Had a clinic interpreter } \\
\hline Yes $(n=415)$ & $\mathrm{N} / \mathrm{A}$ & $74.8 \%$ & \\
\hline No $(n=140)$ & $\mathrm{N} / \mathrm{A}$ & $25.2 \%$ & \\
\hline
\end{tabular}

${ }^{a}$ Analyses were conducted using either $\chi^{2}$ or $t$ test where appropriate. 
Table 3. Association between Language Discordance and Health Education

\begin{tabular}{|c|c|c|c|}
\hline & \multicolumn{3}{|c|}{ Received Less Health Education } \\
\hline & Score $^{a}$ & Unadjusted $\beta(95 \% \mathrm{Cl})$ & Adjusted $^{\mathrm{b}} \beta(95 \% \mathrm{Cl})$ \\
\hline $\begin{array}{l}\text { Language } \\
\text { concordant }\end{array}$ & 2.11 & $\mathrm{REF}$ & $\mathrm{REF}$ \\
\hline $\begin{array}{l}\text { Language } \\
\text { discordant }\end{array}$ & 2.32 & $0.22(0.05,0.38)$ & $0.17(0.01,0.33)$ \\
\hline Interpreter & 2.10 & $-0.003(-0.17,0.17)$ & $0.03(-0.14,0.19)$ \\
\hline No interpreter & 2.74 & $0.63(0.34,0.93)$ & $0.44(0.17,0.72)$ \\
\hline
\end{tabular}

${ }^{a}$ Range $0-3 ; 0=$ most, $3=$ least health education

${ }^{b}$ Adjusted for gender, age, language, marital status, education, years in the United States, and whether patient saw usual doctor at the last visit

discordant patients reported receiving less health education, compared to language-concordant patients. This effect was mitigated when a clinic interpreter was present at the visit. With an interpreter present, patient-provider language discordance was no longer associated with receiving less health education. Not having a clinic interpreter available was significantly associated with receiving less health education in both unadjusted and adjusted models.

Table 4 shows the association between language discordance and the quality of interpersonal care. Language-discordant patients reported worse interpersonal care compared to language-concordant patients. Having a clinic interpreter present at the visit did not substantively mitigate this effect.

The next analyses examined the association between language discordance and patient ratings of their providers. As shown in Table 5, language-discordant patients had a $61 \%$ greater odds of rating their providers as fair or poor compared to language-concordant patients. Having an interpreter present did not mitigate this effect, but in fact appeared to exacerbate it. Compared to patients who had languageconcordant providers, patients who were language-discordant but had a clinic interpreter present at the visit were significantly more likely to rate their providers fair or poor, whereas those without an interpreter present were not.

\section{DISCUSSION}

Language barriers between providers and patients result in poor quality care. Our study found that LEP patients with language-discordant providers were less likely to receive health education compared to those with language-concordant providers. They also reported worse interpersonal care and were less satisfied overall with their providers.
In language-discordant visits without a clinic interpreter, LEP patients were significantly less likely to receive health education. When an interpreter was available, our results indicated that the degree of health education received was similar to language-concordant visits. In other words, having a clinic interpreter allowed health education to occur, whereas not having an interpreter limited the discussion of health promotion issues.

In contrast, having a clinic interpreter present during language-discordant visits did not mitigate the disparity in the quality of interpersonal care for language-discordant visits compared to language-concordant visits. In fact, patients who used an interpreter had twice the odds of rating their provider as fair or poor compared to those with language-concordant providers.

The findings of our study suggest that having language concordance between providers and patients is still the optimal situation. When a language barrier exists between doctors and patients, having a clinic interpreter present will allow the transmission of information such as health education. However, a clinic interpreter may not completely ameliorate the language barrier and may interfere with other aspects of the patient-provider relationship. Interpersonal care and patient satisfaction were lower in these visits compared to visits where patients and providers spoke the same language and did not need an intermediary person to translate.

Our findings are consistent with previous studies conducted among Spanish-speaking patients. A study of LEP Spanish speakers conducted in a hospital emergency department found that patients with language-concordant providers reported the highest levels of understanding of their diagnoses and treatment plans. ${ }^{20}$ Although having an interpreter was better than not having one, patients with language-concordant physicians reported the best outcomes. In another study of communica-

Table 4. Association between Language Discordance and Interpersonal Care

\begin{tabular}{|c|c|c|c|}
\hline & \multicolumn{3}{|c|}{ Lower Ratings of Interpersonal Care } \\
\hline & Score ${ }^{a}$ & Unadjusted $\beta$ (95\% $\mathrm{Cl})$ & Adjusted $^{\mathrm{b}} \beta(95 \% \mathrm{Cl})$ \\
\hline $\begin{array}{l}\text { Language } \\
\text { concordant }\end{array}$ & 2.37 & $\mathrm{REF}$ & $\mathrm{REF}$ \\
\hline $\begin{array}{l}\text { Language } \\
\text { discordant }\end{array}$ & 2.60 & $0.24(-0.04,0.51)$ & $0.28(0.01,0.57)$ \\
\hline Interpreter & 2.46 & $0.09(-0.21,0.39)$ & $0.25(-.04,0.54)$ \\
\hline No interpreter & 2.88 & $0.51(.00,1.03)$ & $0.36(-0.18,0.89)$ \\
\hline
\end{tabular}

${ }^{a}$ Range 0-9; $0=$ highest, $9=$ lowest rating of interpersonal care

${ }^{b}$ Adjusted for gender, age, language, marital status, education, years in the United States, and whether patient saw usual doctor at the last visit 
Table 5. Association Between Language Discordance and Ratings of the Provider

\begin{tabular}{|c|c|c|c|}
\hline & \multicolumn{3}{|c|}{ Fair/Poor Rating of the Provider } \\
\hline & Fair/Poor Rating (\%) & Unadjusted OR $(95 \% \mathrm{Cl})$ & Adjusted $^{\mathrm{a}}$ OR $(95 \% \mathrm{Cl})$ \\
\hline $\begin{array}{l}\text { Language } \\
\text { concordant }\end{array}$ & 11.75 & $\mathrm{REF}$ & $\mathrm{REF}$ \\
\hline $\begin{array}{l}\text { Language } \\
\text { discordant }\end{array}$ & 16.06 & $1.44(0.92,2.23)$ & $1.61(0.97,2.67)$ \\
\hline Interpreter & 16.58 & $1.49(0.87,2.57)$ & $2.10(1.14,3.86)$ \\
\hline No interpreter & 15.07 & $1.33(0.71,2.50)$ & $1.05(0.51,2.15)$ \\
\hline
\end{tabular}

aAdjusted for gender, age, language, marital status, education, years in the United States, and whether patient saw usual doctor at the last visit

tion, language-concordant visits resulted in better interpersonal care compared to visits that required an interpreter. ${ }^{30}$ In language-discordant visits, patients were more likely to have their comments ignored by the providers, even in the presence of an interpreter. Other studies conducted among patients recruited from a walk-in clinic $^{31}$ and hospital emergency department $^{21}$ also found that patients who communicated through an interpreter were less satisfied with their providers overall and less satisfied with their providers' interpersonal care compared to those with language-concordant providers.

There are several limitations to our study. We only studied Asian-American patients who spoke Vietnamese, Cantonese, or Mandarin Chinese. Our results may not be generalizable to patients of other racial/ethnic groups who speak other languages, although the consistency of our results with other studies in Spanish-speaking populations is noteworthy. We also examined only patients who had a visit to a primary care provider within the last month. Our results may not be generalizable to those who, because of linguistic or other barriers, did not receive medical care recently. In addition, our health education measure included discussions about smoking, which may not be relevant for nonsmokers. However, it is unlikely that this affected our findings, as smokers and nonsmokers were likely to have been evenly distributed across language concordant versus discordant providers. Although we measured whether or not the patient used an interpreter provided by the clinic, we were not able to ascertain whether the interpreter was ad hoc staff or professionally trained. Ad hoc interpreters are "individuals whose primary job function in the health care setting is something other than interpretation," whereas professional interpreters are "those individuals whose sole function in the health care setting is to interpret."32 Studies have generally found fewer errors in medical interpretation when professional interpreters were utilized instead of ad hoc staff or family members. ${ }^{33-35}$ Finally, because of the study's cross-sectional design, we can only determine associations and not causality.

Nevertheless, this is 1 of the largest studies of language discordance and interpreter use among LEP patients. It has some important policy implications. First, in language-discordant visits, it is unlikely that much health education can take place without an interpreter. An interpreter is essential to overcome the language barrier and allow meaningful communication to occur. The majority of LEP patients in the United States still lack access to interpreter services. ${ }^{36}$ The use of interpreters has been linked to more appropriate medical and preventive care services ${ }^{37,38}$ and follow-up. ${ }^{16}$ Having access to professional interpreters may also be cost-saving overall, especially in the context of visits to the emergency department. ${ }^{39,40}$ The U.S. Department of Health and Human Services recognized the lack of adequate interpretation as a form of discrimination, and developed a set of mandates and guidelines for culturally and linguistically appropriate services (CLAS). ${ }^{41}$ The CLAS standards require that health care organizations offer and provide language assistance services to LEP patients, and exclude the use of family members as interpreters except by the specific request of the patient. Yet most LEP patients with language-discordant providers still do not have access to interpreters but rather "do the best they can in English." ${ }^{19}$ In a recent study done in California, only 9\% had access to a professional interpreter, whereas the majority relied on family members or friends for translation. ${ }^{19}$ The health care system needs to invest in the training of more professional interpreters and also in providing reimbursement for their services. ${ }^{42}$

However, having access to a professional interpreter is only the first step in overcoming the language barrier. Our study, similar to other studies among Spanish-speakers, ${ }^{20,21,31}$ suggests that interpersonal care and patient satisfaction may still be lower for language-discordant visits compared to visits where patients and providers are able to communicate directly without an intermediary. In fact, our findings suggest that, whereas having an interpreter present may facilitate the transmission of information, it may also negatively affect patients' opinions about the quality of their health care providers. One way to improve interpersonal care and satisfaction may be to provide more training for interpreters and for providers. There are currently no minimum requirements for medical interpreter training. The National Council on Interpreting in Health Care recommends at least 40 hours of instruction on medical terminology, interpreting skills, ethical issues, role playing, and cultural awareness. ${ }^{43}$ In addition, providers also need more training on how to optimally use interpreters. In a recent study of clinicians who provide care to LEP patients, the majority of clinicians reported difficulties eliciting exact symptoms, explaining treatment, and eliciting patient preferences, even with the use of an interpreter. ${ }^{44}$ However, providers who had previous training on how to use interpreters appropriately were the most satisfied with their ability to communicate with LEP patients.

Although interpreters are a necessary solution to the problem of language barriers in health care, our findings suggest they are likely to be an imperfect one. It remains important that our health care system recruit and train more bilingual providers to meet the health care needs of an increasingly diverse population. Increasing recruitment and retention of 
bilingual students into medical school will be a first step toward providing more language-concordant care for LEP Americans.

The numbers of LEP patients in the United States are unlikely to diminish. Providers and health care systems must be prepared to take care of these patients. Ways to reimburse for professional interpreter services need to be incorporated into the current health care payment system. Furthermore, the quality of interpreter services must be monitored. Finally, federal, state, and local health organizations should provide incentives for the recruitment of bilingual medical providers to serve in geographic areas with a large number of LEP patients. These policies can lead to narrowing the gap and improving medical care for LEP patients.

Acknowledgment: The authors thank the patients and staff at the community health centers who participated in this research. This study was funded by the Agency for Healthcare Research and Quality, grant no. R01-HS10316, and the Commonwealth Fund, grant no. 20020110.

\section{Potential Financial Conflicts of Interest: None disclosed.}

Corresponding Author: Quyen Ngo-Metzger, MD, MPH; Division of General Internal Medicine and Primary Care and the Center for Health Policy Research, III Academy, Suite 220, Irvine, CA 926975800, USA (e-mail: Bhngo@uci.edu).

\section{REFERENCES}

1. U.S. Census Bureau. Census 2000 Summary File 3, Matrices P19, P20, PCT13, and PCT14. Washington, DC. 2000.

2. Solis JM, Marks G, Garcia M, Shelton D. Acculturation, access to care, and use of preventive services by Hispanics: findings from HHANES 1982-84. Am J Public Health. 1990;80(suppl): 11-19.

3. Stein JA, Fox SA. Language preference as an indicator of mammography use among Hispanic women. J Natl Cancer Inst. 1990;82(21):1715-16.

4. Timmins CL. The impact of language barriers on the health care of Latinos in the United States: a review of the literature and guidelines for practice. J Midwifery Womens Health. 2002;47(2):80-96.

5. Kirkman-Liff B, Mondragon D. Language of interview: relevance for research of southwest Hispanics. Am J Public Health. 1991;81 (11):1399-404, Nov.

6. Weech-Maldonado R, Morales LS, Spritzer K, Elliott M, Hays RD. Racial and ethnic differences in parents' assessments of pediatric care in Medicaid managed care. Health Serv Res. 2001;36(3):575-94

7. Morales LS, Cunningham WE, Brown JA, Liu H, Hays RD. Are Latinos less satisfied with communication by health care providers? J Gen Intern Med. 1999;14(7):409-17.

8. Carrasquillo O, Orav EJ, Brennan TA, Burstin HR. Impact of language barriers on patient satisfaction in an emergency department. J Gen Intern Med. 1999;14(2):82-7.

9. Weech-Maldonado R, Morales LS, Elliott M, Spritzer K, Marshall G, Hays RD. Race/ethnicity, language, and patients' assessments of care in Medicaid managed care. Health Serv Res. 2003;38(3):789-808.

10. John-Baptiste A, Naglie G, Tomlinson G, et al. The effect of English language proficiency on length of stay and in-hospital mortality. J Gen Intern Med. 2004;19(3):221-8.

11. Divi C, Koss R, Schmaltz S, Loeb J. Language proficiency and adverse events in US hospitals: a pilot study. Int J Qual Health Care. 2007;19 (2):60-7.

12. Weech-Maldonado R, Elliott MN, Morales LS, Spritzer K, Marshall GN, Hays RD. Health plan effects on patient assessments of Medicaid managed care among racial/ethnic minorities. J Gen Intern Med. 2004; 19(2): 136-45.

13. Woloshin S, Bickell NA, Schwartz LM, Gany F, Welch HG. Language barriers in medicine in the United States. JAMA. 1995;273(9):724-8.
14. Perez-Stable EJ, Napoles-Springer A, Miramontes JM. The effects of ethnicity and language on medical outcomes of patients with hypertension or diabetes. Med Care. 1997;35(12):1212-19.

15. Seijo R, Gomez H, et al. Acculturation, access to care, and use of preventive services by Hispanics: findings from HHANES 1982-84. Am J Public Health. 1991;80(suppl): 11-9.

16. Sarver J, Baker DW. Effect of language barriers on follow-up appointments after an emergency department visit. J Gen Intern Med. 2000;15 (4):256-64.

17. Wilson E, Chen AH, Grumbach K, Wang F, Fernandez A. Effects of limited English proficiency and physician language on health care comprehension. J Gen Intern Med. 2005;20(9):800-6.

18. Gandhi TK, Burstin HR, Cook EF, et al. Drug complications in outpatients. J Gen Intern Med. 2000;15(3):149-54

19. New California Media (NCM). Bridging Language Barriers in Health Care: Public Opinion Survey of California Immigrants from Latin America, Asia and the Middle East: The California Endowment; 2003.

20. Baker DW, Parker RM, Williams MV, Coates WC, Pitkin K. Use and effectiveness of interpreters in an emergency department. JAMA. 13 1996;275(10):783-8.

21. Baker DW, Hayes R, Fortier JP. Interpreter use and satisfaction with interpersonal aspects of care for Spanish-speaking patients. Med Care. 1998;36(10): 1461-70.

22. U.S. Census Bureau. General demographic characteristics for the Asian population. http://www.census.gov/population/cen2000/phc-t15/ tab01.pdf and http://www.census.gov/population/cen2000/phc-t15/ tab04.pdf [web page]. 2002. Accessed Feb 2, 2007, 2007.

23. Ngo-Metzger $\mathbf{3}$, Massagli MP, Clarridge B, et al. Patient-centered quality measures for Asian Americans: research in progress. Am J Med Qual. 2000;15(4): 167-73.

24. Ngo-Metzger Q, Massagli MP, Clarridge BR, et al. Linguistic and cultural barriers to care: perspectives of Chinese and Vietnamese immigrants. J Gen Intern Med. 2003;18:44-52.

25. Ngo-Metzger 3, Kaplan S, Sorkin DH, Clarridge BR, Phillips RS. Surveying minorities with limited-English proficiency: does data collection method affect data quality among Asian Americans? Med Care. 2004;42(9):893-900.

26. Cleary PD, Edgman-Levitan S, Roberts M, et al. Patients evaluate their hospital care: a national survey. Health Aff (Millwood). Winter 1991;10 (4):254-67.

27. Consumer Assessment of Healthcare Providers and Systems (CAHPS). Fact sheet. AHRQ Publication No. 00-PO47. Agency for Health Care Research and Quality [web]. Available at: https://www.cahps.ahrq.gov/ content/cahpsOverview/OVER_Intro.asp. Accessed April 4, 2007.

28. SAS Statistical Software [computer program]. Version 8.1 for Windows. Cary, NC; 1999

29. Software for the Statistical Analysis of Correlated Data [computer program]. Version 9 for Windows [computer program]. Version. Research Triangle Park, NC: SUDAAN; 2005.

30. Rivadeneyra R, Elderkin-Thompson V, Silver RC, Waitzkin H. Patient centeredness in medical encounters requiring an interpreter. Am J Med. 2000;108(6):470-4

31. Lee LJ, Batal HA, Maselli JH, Kutner JS. Effect of Spanish interpretation method on patient satisfaction in an urban walk-in clinic. J Gen Intern Med. 2002;17(8):641-5.

32. Grantmakers in Health (GIH). In the Right Words: Addressing Language and Culture in Providing Health Care. 2003 (Issue Brief \#18).

33. Elderkin-Thompson V, Silver RC, Waitzkin H. When nurses double as interpreters: a study of Spanish-speaking patients in a US primary care setting. Soc Sci Med. 2001;52(9):1343-58.

34. Laws MB, Heckscher R, Mayo SJ, Li W, Wilson IB. A new method for evaluating the quality of medical interpretation. Med Care. 2004;42(1):71-80.

35. Flores G, Laws MB, Mayo SJ, et al. Errors in medical interpretation and their potential clinical consequences in pediatric encounters. Pediatrics. 2003;111(1):6-14

36. Doty M. Hispanic Patients' Double Burden: Lack of Health Care Insurance and Limited English. The Commonwealth Fund. 2003.

37. Tocher TM, Larson E. Quality of diabetes care for non-English-speaking patients. A comparative study. West J Med. 1998;168(6):504-11.

38. Jacobs EA, Lauderdale DS, Meltzer D, Shorey JM, Levinson W, Thisted RA. Impact of interpreter services on delivery of health care to limited-English-proficient patients. J Gen Intern Med. 2001;16(7):468-74.

39. Bernstein J, Bernstein E, Dave A, et al. Trained medical interpreters in the emergency department: effects on services, subsequent charges, and 
follow-up. J Immigr Health. 2002;4(4):171-6.

40. Hampers LC, McNulty JE. Professional interpreters and bilingual physicians in a pediatric emergency department: effect on resource utilization. Arch Pediatr Adolesc Med. 2002;156(11):1108-13.

41. U.S. Department of Health and Human Services. Assuring Cultural Competence in Health Care: Recommendations for National Standards and an Outcomes-Focused Research Agenda (CLAS). Rockville: DHHS, Agency for Health care Research and Quality; 2001.
42. Youdelman M, Perkins J. Providing Language Interpretation Services in Health Care Setting: Examples from the Field. New York, NY: The Commonwealth Fund; 2002.

43. National Council on Interpreting in Health Care (NCIHC). The Role of the Health Care Interpreter: An Evolving Dialogue. 2001.

44. Karliner LS, Perez-Stable EJ, Gildengorin G. The language divide. The importance of training in the use of interpreters for outpatient practice. J Gen Intern Med. 2004;19(2):175-83. 